Institute of $\mathbf{F}_{\text {ood and }} \mathbf{A}_{\text {gricultural }} \mathbf{S}_{\text {ciences }}$

\title{
Infectivity and Persistence of Ss Nematodes on Pasture Mole Crickets in South-Central Florida ${ }^{1}$
}

\author{
Martin B. Adjei, Grover C. Smart, Jr., and Byron J. Adams ${ }^{2}$
}

The Mole Cricket Task Force of the Institute of Food and Agricultural Sciences (IFAS), University of Florida, has applied approximately 22 billion beneficial nematodes to more than 20 ranches in south-central Florida to help suppress damaging mole crickets and bring economic relief to livestock producers. The results on infectivity (defined as the ability to enter a host) and persistence (ability to offer-long term control) are encouraging.

\section{Pilot Project}

Initially, in September of 2000, nematodes were applied in strips to distribute $1 / 8,1 / 4$, and $1 / 2$ billion nematodes/acre on a 24 -acre pasture in Polk City. Some plots in that pasture did not receive nematodes. Each treatment was replicated three times. This experiment was done to determine the rate of nematode spread within mole cricket populations on pasture at reduced nematode application rates. Six pitfall traps were installed on each plot and the number of mole crickets trapped were recorded weekly. Samples of mole crickets were analyzed for nematode infection monthly.
Mole crickets are very mobile and infected mole crickets spread the nematodes throughout that pasture within a few months (Table 1). In the fall of 2001, the entire pasture was flooded for several days and adult mole crickets relocated. Results show that the nematodes persisted in the soil through the fall and subsequent winter months and resumed breeding in adult mole crickets during the spring of 2002. The current mean nematode infection in mole cricket population on that pasture was $34 \%$ regardless of initial nematode application rate (Table 1). Mole cricket numbers have declined by $65-80 \%$ and pasture grass canopy ground cover in the spring of 2002 was $58-100 \%$, representing a 45 to $200 \%$ increase relative to grass cover estimated in 2000 .

\section{Mole Cricket State Program Reestablishment}

To promote widespread distribution of mole cricket-killing nematodes in Florida, the IFAS Mole Cricket Task Force extended its membership to include the Florida Department of Agriculture and Consumer Services Department of Primary Industries (FDACS-DPI), allied industrialists, and producer organizations such as the Florida

1. This document is ENY-669, one of a series of the Entomology and Nematology Department, Florida Cooperative Extension Service, Institute of Food and Agricultural Sciences, University of Florida. Original publication date August 2002. Visit the EDIS Web site at http://edis.ifas.ufl.edu.

2. M.B. Adjei, assistant professor, Range Cattle Research and Education Center, Ona, G.C. Smart, Jr., professor, and B.J. Adams, assistant professor, Entomology and Nematology Department, Florida Cooperative Extension Service, Institute of Food and Agricultural Sciences, University of Florida, Gainesville, 32611 . 
Cattlemen's Association and Florida Turf

Association in 2000. The enlarged Task Force successfully recruited MicroBio (U.K.), a subsidiary of Becker Underwood (USA), as the sole commercial producer and distributor of the mole cricket nematode (Steinernema scapterisci, Ss). MicroBio named their nematode product Nematac ${ }^{\circledR}$ S. The Florida Legislature provided the task force, through FDACS-DPI, with $\$ 300,000$ in 2001 to reestablish a Mole Cricket State Program. The purpose of those funds was to support research/demonstration activities on biological control of mole crickets and conduct area-wide testing of the nematodes in Florida.

\section{Phase 1}

For the first phase of the State Program, Nematac S donated by MicroBio was applied in the spring of 2001 at seven ranches in Hardee, DeSoto, Pasco, and Polk counties. Sites had no pre-application history of $S s$ based on trapped mole cricket examination. Nematodes were applied with our slit-injector machine in strips at the $1 / 4$ and $1 / 8$ billion rates. Few adult mole crickets were trapped at these sites in the fall of 2001. In spring 2002, we observed no differences between the effects of $1 / 8$ and $1 / 4$ billion rates of nematode application on infection level, hence, the average nematode infection in mole crickets over treatments is shown in Table 2.

\section{Phase 2}

The second phase of the State Mole Cricket project on pasture involved nematode application to pasture and sod farms on 13 sites in south-central Florida. Nematac $S$ product was applied with the slit-injector in strips at the $1 / 8$ billion nematodes/A to all sites during fall 2001. Updates on nematode infection in trapped mole crickets from pastures and sods are provided in Tables 3 and 4, respectively. At Hollingsworth ranch in DeSoto Co., 1 out of the 5 pre-application mole crickets trapped was infected with the nematode. This was probably due to previous nematode application to turfgrass around the area in the 1990s. No other site had a pre-application history of nematodes.

With the exception of Deseret and Yates ranches, the nematodes seem to be spreading fast on pasture based on February-April, 2002 infection ratings

(Table 3) and on sod farms too (Table 4).

\section{Summary}

The number of mole crickets trapped for evaluation rose in March and April 2002 making the data more reliable. Percentage of trapped mole crickets infected with nematodes ranged from 10 to 63\% in March and 0 to 82\% in April, 2002 for spring 2001-treated pasture sites (Table 2) and from 5 to 80 in March and 0 to 83 in April 2002 for fall 2001-treated pasture sites (Table 3). This suggests that successful nematode establishment is possible with either fall or spring application provided soil moisture is adequate. The level of infection on sod farms also ranged from 0 to $85 \%$ (Table 4). Bethel, Schroder-Manatee, and $\mathrm{H} \& \mathrm{H}$ sod growers applied their nematodes with a sprayer rig followed by $1 "$ irrigation at Schroder-Manatee and Bethel but not at $\mathrm{H} \& \mathrm{H}$ sod farms. The slit injector machine was used to apply nematodes at Duda sod farm. Irrigation after spray application also seemed to promote nematode establishment. Most infected mole crickets will die in the soil and will not be recovered using trapping methods, so percentage infection reported is likely to be quite conservative.

In all three studies, the percentage of trapped mole crickets infected with the nematodes increased steadily from winter through spring in 2002. Infected mole crickets are expected to die within a few days. The nematodes have done a good job in breeding within the mole crickets and their offspring continue to attack other adult mole crickets in 19 of the 21 test sites. Nematodes have persisted in the soil through flood and cold winter months. There has been dramatic recovery of pastures in most cases.

We will continue to monitor the nematode spread and grass recovery. Meanwhile, the nematodes became commercially available to ranchers and sod growers this spring and marketing information may be obtained from Becker Underwood's local representative, Gabe Diaz-Saavedra, at 941-350-7291. Information on application can be obtained from your local extension agent or from the Range Cattle REC at 863-735-1314 ext 211. 
Table 1. Mole crickets infected with nematodes after September 2000 application.

\begin{tabular}{|c|c|c|c|c|c|}
\hline \multirow[b]{2}{*}{ Date } & \multicolumn{4}{|c|}{ Amount of pasture plot treated } & \multirow[b]{2}{*}{ LSD 0.05} \\
\hline & $1 / 2$ & $1 / 4$ & $1 / 8$ & 0 & \\
\hline & \multicolumn{4}{|c|}{ (\# of mole crickets trapped), \% infected } & \\
\hline Apr. 2001 & (21) 86 & (19) 84 & (20) 80 & (17) 41 & 15 \\
\hline May 2001 & (5) 80 & (7) 43 & (4) 50 & (6) 33 & 17 \\
\hline Feb. 2002 & (5) 60 & (1) 100 & (10) 20 & (4) 50 & 25 \\
\hline Mar. 2002 & (6) 33 & (3) 33 & (1) 0 & (2) 50 & 22 \\
\hline Apr. 2002 & (17) 30 & (13) 23 & (18) 42 & (16) 38 & 18 \\
\hline
\end{tabular}

Table 2. Monthly percentage of trapped mole crickets infected with beneficial nematodes following spring 2001 Nematac $S$ application.

\begin{tabular}{|c|c|c|c|c|c|c|c|c|}
\hline & & \multicolumn{7}{|c|}{ Date } \\
\hline Ranch & County & $\begin{array}{l}\text { Apr. } \\
2001\end{array}$ & $\begin{array}{l}\text { May } \\
2001\end{array}$ & $\begin{array}{l}\text { Jun. } \\
2001\end{array}$ & $\begin{array}{l}\text { Dec. } \\
2001\end{array}$ & $\begin{array}{l}\text { Feb. } \\
2002\end{array}$ & $\begin{array}{l}\text { Mar. } \\
2002\end{array}$ & $\begin{array}{l}\text { Apr. } \\
2002\end{array}$ \\
\hline H. Keller & Hardee & (14) 57 & (15) 33 & (9) 55 & (3) 33 & (15) 67 & (12) 50 & (42) 45 \\
\hline Peace River & Hardee & -- -- & -- -- & (2) 0 & (0) -- & (6) 67 & (8) 63 & (11) 82 \\
\hline L. Bryant & Hardee & & & & & (0) -- & (2) 50 & (3) 0 \\
\hline W. Wise & DeSoto & (2) 50 & (5) 80 & (1) 100 & (4) 0 & (0) -- & (24) 25 & (7) 14 \\
\hline Al Bar & Pasco & -- -- & -- -- & -- -- & -- -- & -- -- & -- -- & (29) 70 \\
\hline M. Nutt & Pasco & --- & -- -- & --- & -- -- & -- -- & -- -- & (6) 50 \\
\hline H. Combee & Polk & --- & --- & --- & -- -- & (11) 36 & (21) 10 & (38) 29 \\
\hline
\end{tabular}


Table 3. Percentage of trapped mole crickets infected with beneficial nematodes following fall 2001 application of Nematac $S$ at $1 / 8$ billion nematodes/A to pastures.

\begin{tabular}{|c|c|c|c|c|c|c|}
\hline Ranch & County & Fall $2001^{*}$ & Jan. 2002 & Feb. 2002 & Mar. 2002 & Apr. 2002 \\
\hline & & \multicolumn{5}{|c|}{ - . - . - (\# of trapped mole crickets) \% infection - . . - . } \\
\hline D. Barber & Oseola & (23) 0 & $(0)--$ & (6) 83 & $(0)--$ & (35) 71 \\
\hline Tom Kibler & Manatee & (4) 0 & $(0)--$ & $(0)--$ & $(10) 70$ & (4) 0 \\
\hline M. Taylor & Manatee & (2) 0 & $(0)--$ & (1) 100 & $(10) 50$ & (13) 38 \\
\hline B. Keating & Hardee & (3) 0 & (4) 25 & (0) -- & (4) 50 & (16) 83 \\
\hline J.B. Starkey & Pasco & (6) 0 & --- & --- & -- -- & (10) 30 \\
\hline Yates & Orange & (2) 0 & (0) -- & (0) -- & (0) -- & (1) 0 \\
\hline
\end{tabular}

Table 4. Percentage of trapped mole crickets infected with beneficial nematodes following fall 2001 application of Nematac $S$ at $1 / 8$ billion nematodes/A to sod farms.

\begin{tabular}{|c|c|c|c|c|c|c|}
\hline Sod farm & County & Fall 2001 & Jan. 2002 & Feb. 2002 & Mar. 2002 & Apr. 2002 \\
\hline & & \multicolumn{5}{|c|}{ - - - - (\# of trapped mole crickets) \% infection - . - - - } \\
\hline Duda & Polk & (9) 0 & (1) 100 & $(0)--$ & (13) 85 & (8) 63 \\
\hline Bethel & DeSoto & (9) 0 & $(0)--$ & $(0)--$ & (4) 75 & (8) 38 \\
\hline $\mathrm{H} \& \mathrm{H}$ & Osceola & (1) 0 & $(0)--$ & (1) 0 & (10) 0 & (6) 17 \\
\hline
\end{tabular}

